\title{
Steering drift and wheel movement during braking: parameter sensitivity studies
}

\author{
J Klaps ${ }^{1}$ and A J Day ${ }^{2 *}$ \\ ${ }^{1}$ Ford Motor Company, Belgium \\ ${ }^{2}$ School of Engineering, Design and Technology, University of Bradford, Bradford, UK
}

\begin{abstract}
In spite of the many significant improvements in car chassis design over the past two decades, steering drift during braking where the driver must apply a corrective steering torque in order to maintain course can still be experienced under certain conditions while driving. In the past, such drift, or 'pull', would have been attributed to side-to-side braking torque variation [1], but modern automotive friction brakes and friction materials are now able to provide braking torque with such high levels of consistency that side-to-side braking torque variation is no longer regarded as a cause of steering drift during braking. Consequently, other influences must be considered. This paper is the first of two papers to report on an experimental investigation into braking-related steering drift in motor vehicles. Parameters that might influence steering drift during braking include suspension compliance and steering offset, and these have been investigated to establish the sensitivity of steering drift to such parameters. The results indicate how wheel movement arising from compliance in the front suspension and steering system of a passenger car during braking can be responsible for steering drift during braking. Braking causes changes in wheel alignment which in turn affect the toe steer characteristics of each wheel and therefore the straight-line stability during braking. It is concluded that a robust design of suspension is possible in which side-to-side variation in toe steer is not affected by changes in suspension geometry during braking, and that the magnitude of these changes and the relationships between the braking forces and the suspension geometry and compliance require further investigation, which will be presented in the second paper of the two.
\end{abstract}

Keywords: vehicle, automotive, steering, braking, drift, robust design

\section{INTRODUCTION}

'Steering drift during braking' refers to any minor deviation of a vehicle from a straight-line while braking. By today's standards of vehicle performance, handling and drivability, even minor deviation of this type is unacceptable. In contrast, the term 'brake pull' has been used to describe a major deviation of the vehicle during braking, and has, in the past, often been identified with unequal torque generated by the friction brake on each of the front (steered) wheels of a motor vehicle. The potential danger of brake pull has been recognized by vehicle designers for many years, and the consistency of performance of modern friction brakes together with modern designs of suspension and steering geometry mean that, if brake pull occurs nowadays, there is a

The MS was received on 12 February 2003 and was accepted after revision for publication on 29 August 2003.

* Corresponding author: School of Engineering, Design and Technology, University of Bradford, Bradford BD7 1DP, UK. serious fault that requires immediate attention. However, the causes of steering drift during braking need to be understood at the design stage, and this paper starts to quantify the parameters that can affect suspension and steering geometry changes under wheel braking torque loads as a possible cause of steering drift during braking in a modern car, in order to be able to minimize the sensitivity of the vehicle to its operational environment. It is generally considered that wear of the suspension system, particularly joints and bushings, could increase the sensitivity of the vehicle to its operational environment in terms of steering drift during braking, and this is one of the reasons why annual vehicle tests, required by law in many countries, require the rectification of worn suspension components.

The friction brakes on each wheel of a motor vehicle have to meet the legal requirements of stopping in a safe, controlled and predictable fashion. Most modern passenger cars and light commercial vehicles are fitted with front disc brakes and rear disc or drum brakes. Important factors for controlling braking stability 
include control of the clearance between the friction material and rotor, temperature stability of the friction pair such as [2] brake fade, excessive thermal distortion and surface cracking and rotor composition, e.g. trace elements of titanium and vanadium [3].

Each brake generates a braking torque which is reacted through the suspension components by the subframe or chassis system [2]. Although the suspension components may be symmetrical side to side, the subframe and/or chassis system are generally not. The suspension, subframe and chassis systems are compliant to a greater or lesser extent: compliance in the suspension system may be necessary to achieve a good ride characteristic, but an undesirable side effect can be 'compliance steer', which results from the application of lateral or longitudinal forces at the tyre contact patch. These forces deflect the suspension bushings and change the camber and toe angles $[4,5]$, and thus are considered to be one of the biggest contributors to straight-line stability during braking.

Compliance can be introduced into vehicle suspension systems by:

(a) elastomeric (rubber) suspension pivots,

(b) rubber-mounted cross-members,

(c) rubber-mounted steering racks and other steering joints,

(d) component deflection under load, including suspension links, steering links and the chassis mounts for suspension and steering.

Deflections resulting from the braking forces and torques can therefore be responsible for different wheel movements on each side of the car because, even though the forces may be the same side to side, the compliances may not. The kinematic effect of this can be to create dynamic changes in wheel alignment and steering geometry during braking, particularly on the front wheels where braking loads are highest. The alignment or steering geometry parameters of the front (steered) wheels then needs to be considered.

Four parameters associated with steering geometry that could affect steering drift are toe steer, camber, caster and scrub radius:

1. The toe setting is designed to compensate for the amount the tyres turn away from straight ahead under driving conditions. Poor adjustment of the toe setting can cause unstable straight-line drivability, and a steering reaction is generated if the toe steer angles are different between left and right track. The amount of toe-in or toe-out can also depend on the suspension position relative to the steering gear. Toe-in or toe-out is usually the same in the design ride position but can change in opposite directions during body roll, thereby causing the vehicle to pull to one side.

2. Wheel camber generates camber scrub, because true rolling is achieved only in the centre of the tread. This produces camber steer: positive camber will make the wheels turn away from each other, i.e. toe-out, whereas negative camber will make the wheels turn towards each other, i.e. toe-in. The wheel track must be set to match the design of suspension to counteract the inherent tendency of the wheels to either move away from or towards each other [6].

3. Caster is employed to provide stability through selfaligning of the steered wheels. Decreasing caster will reduce directional stability (and decrease steering effort). In the steered wheels of a motor car, uneven road surfaces cause alternating lateral forces at the centre of the tyre contact patch which can cause moments about the steering axis, resulting in steering disturbances.

4. Scrub radius is the geometric distance between the centre-line of the tyre contact patch and the steering axis at the ground plane [7]. A negative scrub radius can improve the straight-line stability of a vehicle while braking on split $\mu$ conditions or during failure of one brake circuit.

The effects of changes in wheel alignment and steering geometry parameters can be further compounded by tyre performance parameters. Tyre lateral force and selfaligning torque arising from pneumatic trail determine the effective slip angle and total axle lateral forces [8]. A different lateral stiffness between tyres of the left and right track of a vehicle leads to a permanent steering drift, independent of the driving situation. Five tyrerelated parameters that are considered to be associated with steering drift are: tyre inflation pressure, tyre temperature, conicity, ply steer and residual self-aligning torque (RSAT):

1. Higher tyre pressure increases the cornering stiffness: for a given small slip angle, an increase in pressure will give an increase in lateral force. As tyre pressure is decreased, the contact patch becomes longer and the centre of lateral force moves rearward, increasing self-aligning torque.

2. Tyre inflation pressure is temperature dependent.

3. Conicity is the lateral force offset at zero slip angle [8] and acts in the same direction whether the tyre is rolling forwards or backwards. An off-centre belt causes 80 per cent or more of conicity forces, the force sensitivity being typically $30 \mathrm{~N} / \mathrm{mm}$ of belt offset [9]. Ply-steer forces result from the angle of the belt plies; the outer ply exerts the dominant effect, and the direction of the ply-steer lateral force depends on the direction of rolling.

4. Ply-steer forces result from the angle of the belt plies; the outer ply exerts the dominant effect, and the direction of the ply-steer lateral force depends on the direction of rolling [10].

5. For a vehicle to move in a straight line, the sum of the lateral forces acting on the axle must equal zero. 
However, even though the sum of the lateral forces may be zero, the sum of the self-aligning torques acting on the two steering tyres may not be zero [9]. Residual self-aligning torque (RSAT) is a measure of tyre contribution to steering pull; if the total RSAT is zero, there is zero torque steer from the tyres, and therefore no pull. RSAT is related to tyre conicity and ply steer and is the self-aligning torque at the slip angle for which the lateral force becomes zero [8].

Torque steer can be generated when the outboard constant velocity joint of a front wheel drive car is not in line with the wheel spindle because of ride height changes caused by vehicle loading, body roll or weight transfer. As long as the system is symmetrical, the effects on each side of the car will be equal and opposite. However, if the driveshafts are unequal in length, the articulation angles each side will be different and a resultant steering torque will be generated [11]. Torque steer effects can be important under vehicle acceleration, but are not considered here.

\section{PARAMETER SENSITIVITY INVESTIGATION}

\subsection{Objective}

The purpose of the first test work was to find out which parameters in the front suspension/steering/braking system might have the greatest influence on steering drift during braking.

\subsection{Test equipment and procedure}

Two identical specification test cars were selected of a front wheel drive family saloon. This particular model of vehicle was selected because it was a standard car manufactured by the company sponsoring the research.
The front suspension was a McPherson strut design, with the lower wishbone pivoted to the front subframe via rubber bushes to provide lateral and longitudinal location. The subframe was mounted to the vehicle body via rubber mounts. The top of the strut was mounted directly to the vehicle body via rubber bushing at the suspension turrets. This design of suspension offered the opportunity to adjust certain parameters for the purposes of investigation. Instrumentation and equipment to measure the following parameters were installed on each car for initial road tests to investigate the sensitivity of the five parameters A to E explained next.

\subsection{Experimental design}

An experiment was designed according to a statistical design of experiment methodology, based on a fivefactor two-level L16 orthogonal array [12]. This enabled the main effects to be identified and gave no confounding between the major two-way interactions. The five factors are explained in Table 1. The levels selected were the largest practically possible, considered within the constraints of safety and/or clearance between, for example, the tyres and the body in the case of the wheel offset. Side-to-side variation in the braking force (e.g. from different brake discs or friction materials) was not included since this was a known effect.

The tyre and brake temperature (factor A) was considered to be dependent upon braking under different driving styles. Hot brakes/tyres could produce different braking torques which could influence steering drift during braking.

The suspension geometry toe-steer curve (factor B), the steering gear housing/engine subframe reinforcement cover (factor C) and the front suspension lower wishbone rear bush stiffness (factor D) were selected because

Table 1 Experimental factors and settings for parameter sensitivity tests

\begin{tabular}{|c|c|c|}
\hline Factor & Level & Setting \\
\hline Tyre and brake temperature & $\begin{array}{l}\mathrm{A}- \\
\mathrm{A}+\end{array}$ & $\begin{array}{l}\text { Tyres and brakes cold } \\
\text { Tyres and brakes hot }\end{array}$ \\
\hline $\begin{array}{l}\text { Suspension geometry toe-steer } \\
\text { curve }\end{array}$ & $\mathrm{B}-$ & $\begin{array}{l}\text { Standard (without spacer) between the steering gear housing } \\
\text { and subframe } \\
2.5 \mathrm{~mm} \text { spacer between the steering gear housing and subframe } \\
\text { on the left-hand side }\end{array}$ \\
\hline $\begin{array}{l}\text { Steering gear housing/engine } \\
\text { subframe reinforcement cover }\end{array}$ & $\begin{array}{l}\mathrm{C}- \\
\mathrm{C}+\end{array}$ & $\begin{array}{l}\text { Without reinforcement } \\
\text { With reinforcement }\end{array}$ \\
\hline $\begin{array}{l}\text { Front suspension lower wishbone } \\
\text { rear bush stiffness }\end{array}$ & $\mathrm{D}+$ & $\begin{array}{l}\text { 'Voided rear bush' ( This bush had voids moulded in to provide } \\
\text { different stiffness in two orthogonal directions: } 1200 \mathrm{~N} / \mathrm{mm} \text { in } \\
\text { the } x \text { direction and } 4000 \mathrm{~N} / \mathrm{mm} \text { in the } y \text { direction. This was } \\
\text { the standard arrangement.) } \\
\text { 'Non-voided' bush ( } 5000 \mathrm{~N} / \mathrm{mm} \text { radial stiffness) }\end{array}$ \\
\hline Wheel offset ( $y$ direction) & $\begin{array}{l}\mathrm{E}- \\
\mathrm{E}+\end{array}$ & $\begin{array}{l}\text { Standard ( } 49.5 \mathrm{~mm} \text { wheel offset) } \\
\text { With } 6 \mathrm{~mm} \text { thick spacer between the wheel spider and hub } \\
\quad(55.5 \mathrm{~mm} \text { wheel offset, right-hand side only) }\end{array}$ \\
\hline
\end{tabular}


they imparted compliance to the front suspension assembly.

The wheel offset in the $y$ direction (factor E) was chosen to investigate the effect of scrub radius. Two levels for each factor A to E were set as shown in Table 1.

The tests on the two cars were carried out on a $1.2 \mathrm{~km}$ long by $8 \mathrm{~m}$ wide straight test track [13]. The measured response in the experiment was the lateral displacement of the vehicle, measured by the number of carriageway lanes moved from the straight-ahead position during the braking manoeuvre [13].

The test procedure was designed to be representative of actual road usage. After checking the setting and test conditions, the vehicle (unladen weight + driver and observer), fitted with new brakes in 'virgin' condition, was braked to rest in neutral gear from $100 \mathrm{~km} / \mathrm{h}$ at a set deceleration of 30, 50, and $70 \% \mathrm{~g}$ (all brakes operational) with a 'free' (hands-off) steering wheel. The deviation from straight-line braking was measured, and the procedure was repeated to a total five runs from a virgin brake condition. The test runs were conducted in alternate directions along the track to eliminate any directional effects. A cooling lap of approximately $6 \mathrm{~km}$ was driven after each brake application to return the tyres and brakes to the 'cold' condition $(\mathrm{A}-)$. The 'hot' condition test was conducted immediately after the preceding 'cold' test.

\subsection{Results}

The results are summarized in Table 2 .

\section{TESTS TO INVESTIGATE SIGNIFICANT PARAMETERS}

\subsection{Objective}

Having established (section 2) that factor D (the suspension compliance) and factor $\mathrm{E}$ (wheel offset) had a significant effect, further tests were carried out to

Table 2 Results of parameter sensitivity investigation

\begin{tabular}{|c|c|c|}
\hline \multicolumn{2}{|l|}{ Factor } & \multirow{2}{*}{$\begin{array}{l}\text { Effect } \\
\text { Insignificant }\end{array}$} \\
\hline A & Tyre and brake temperature & \\
\hline B & Suspension geometry toe-steer curve & Insignificant \\
\hline $\mathrm{C}$ & $\begin{array}{l}\text { Steering gear housing/engine subframe reinforced } \\
\text { cover }\end{array}$ & $\begin{array}{l}\mathrm{C} \text { - was significantly worse than } \mathrm{C}+\text {, i.e. drift was } \\
\text { increased without the perimeter frame reinforcement } \\
\text { cover. Best suitable level was }+ \text { (with perimeter frame } \\
\text { reinforcement cover) }\end{array}$ \\
\hline $\mathrm{D}$ & $\begin{array}{l}\text { Front suspension lower wishbone rear bush } \\
\text { stiffness }\end{array}$ & $\begin{array}{l}\text { Most significant effect. D+ (non-voided rear bush) } \\
\text { gave smallest steering drift }\end{array}$ \\
\hline $\mathrm{E}$ & Wheel offset & Second most significant effect \\
\hline $\mathrm{A} \times \mathrm{B}$ & $\begin{array}{l}\text { Interaction between }(\mathrm{A}) \text { the tyre and brake } \\
\text { temperature and }(\mathrm{B}) \text { the suspension geometry } \\
\text { toe-steer curve }\end{array}$ & Insignificant \\
\hline $\mathrm{A} \times \mathrm{C}$ & $\begin{array}{l}\text { Interaction between (A) the tyre and brake } \\
\text { temperature and }(\mathrm{C}) \text { the steering gear housing/ } \\
\text { engine subframe reinforced cover }\end{array}$ & Insignificant \\
\hline $\mathrm{A} \times \mathrm{D}$ & $\begin{array}{l}\text { Interaction between (A) the tyre and brake } \\
\text { temperature and (D) the front suspension lower } \\
\text { wishbone rear bush stiffness }\end{array}$ & $\begin{array}{l}\text { Minor interaction effect. When } \mathrm{D} \text { and } \mathrm{A} \text { were both }+ \text {, } \\
\mathrm{A} \times \mathrm{D} \text { became }+ \text { as well, which meant a reduction } \\
\text { in the steering drift. The effect was similar to } \mathrm{D} \text { alone, } \\
\text { but larger than } \mathrm{A} \text { alone (which was insignificant), } \\
\text { indicating that the interaction effect was minor }\end{array}$ \\
\hline $\mathrm{A} \times \mathrm{E}$ & $\begin{array}{l}\text { Interaction between }(A) \text { the tyre and brake } \\
\text { temperature and }(E) \text { the wheel offset }\end{array}$ & Insignificant \\
\hline $\mathrm{B} \times \mathrm{C}$ & $\begin{array}{l}\text { Interaction between (B) the suspension geometry } \\
\text { toe-steer curve and }(\mathrm{C}) \text { the steering gear housing/ } \\
\text { engine subframe reinforced cover }\end{array}$ & Insignificant \\
\hline $\mathrm{B} \times \mathrm{D}$ & $\begin{array}{l}\text { Interaction between (B) the suspension geometry } \\
\text { toe-steer curve and (D) the front suspension } \\
\text { lower wishbone rear bush stiffness }\end{array}$ & Insignificant \\
\hline $\mathrm{B} \times \mathrm{E}$ & $\begin{array}{l}\text { Interaction between (B) the suspension geometry } \\
\text { toe-steer curve and }(\mathrm{E}) \text { the wheel offset }\end{array}$ & Insignificant \\
\hline $\mathrm{C} \times \mathrm{D}$ & $\begin{array}{l}\text { Interaction between }(\mathrm{C}) \text { the steering gear housing/ } \\
\text { engine subframe reinforced cover and (D) the } \\
\text { front suspension lower wishbone rear bush } \\
\text { stiffness }\end{array}$ & Insignificant \\
\hline $\mathrm{C} \times \mathrm{E}$ & $\begin{array}{l}\text { Interaction between }(\mathrm{C}) \text { the steering gear housing/ } \\
\text { engine subframe reinforced cover and }(\mathrm{E}) \text { the } \\
\text { wheel offset }\end{array}$ & Insignificant \\
\hline $\mathrm{D} \times \mathrm{E}$ & $\begin{array}{l}\text { Interaction between }(\mathrm{D}) \text { the front suspension lower } \\
\text { wishbone rear bush stiffness and }(\mathrm{E}) \text { the wheel } \\
\text { offset }\end{array}$ & $\begin{array}{l}\text { Largest significant interaction effect. When } \mathrm{D} \text { is }+ \text {, } \\
\text { and } \mathrm{E} \text { is }+ \text {, then the interaction also becomes }+ \text {. } \\
\text { This has a negative effect on the response (greater } \\
\text { steering drift) }\end{array}$ \\
\hline
\end{tabular}


investigate how steering drift during braking could be reduced or eliminated by adjusting these two factors.

\subsection{Test equipment and instrumentation}

Another car of the same model was fitted with instrumentation that allowed the dynamic longitudinal deflections and forces in the suspension components, the brake forces and the dynamic steering behaviour to be measured. A portable computer with $\mathrm{A} / \mathrm{D}$ converter and measuring acquisition software (DIA/DAGO ${ }^{\circledR}$ ) was used to $\log$ these data [13]. The instrumentation is summarized below:

1. To measure the longitudinal and lateral acceleration and the yaw velocity, a gyrostabilized platform was installed near the centre of gravity which provided measurements independent of the roll and pitch angle of the vehicle.

2. The steering wheel torque and angle were measured with an instrumented steering wheel, which replaced the original steering wheel: a positive steering wheel angle signifies steering to the right (clockwise rotation of the steering wheel by the driver). The same convention applied to the measurement of the steering torque, namely to steer to the right, a positive (clockwise) torque must be applied by the driver. However, it should be noted that, if the vehicle were to drift to the right, then a negative (counterclockwise) torque would have to be applied by the driver to maintain course. This is important in the 'fixed' and 'free' control testing explained in section 3.3 below.

3. To measure the steering tyre rod forces of the rack and pinion power steering, the original tie rods were equipped with strain gauges to sense only tension $(+)$ and compression $(-)$ forces.

4. A Datron Correvit sensor was mounted at the rear of the vehicle to measure the longitudinal speed of the vehicle.

5. To measure the dynamic toe steer and camber angles, the vehicle was equipped with a Zimmer Autokollimator mounted on a lightweight frame. This optical device measured the deflection of a light beam which was projected on to a mirror mounted at the wheel rim.

Full details of the test equipment and instrumentation can be found in reference [13].

\subsection{Test procedure}

The test car was set up in three test configurations:

(a) standard front suspension lower wishbone rear bush stiffness, standard wheel offset;

(b) standard front suspension lower wishbone rear bush stiffness, increased wheel offset; (c) increased front suspension lower wishbone rear bush stiffness, standard wheel offset.

In each configuration a dynamic straight-line braking test was carried out with 'free control', which required the driver to apply no correction to any perceived steering drift during braking. The test procedure was as follows:

1. Drive the test car in a straight line at a speed of $100 \mathrm{~km} / \mathrm{h}$.

2. Apply a braking deceleration of $7 \mathrm{~m} / \mathrm{s}^{2}$ to rest (engine braking is included; the clutch is disengaged just before the vehicle comes to rest).

Two different steering methods were employed: free control and fixed control. Free control meant that the vehicle was driven 'hands-off' the steering wheel; in this case the steering wheel torque was zero. Under fixed control the steering wheel angle was held at zero. The recording of the measured parameters was started $2 \mathrm{~s}$ before braking commenced, and finished $2 \mathrm{~s}$ after the vehicle came to rest. A deceleration of $7 \mathrm{~m} / \mathrm{s}^{2}$ was chosen because this showed the most repeatable results without any influence of the anti lock braking system. The control and measured parameters are summarized below.

Control parameters:

1. Longitudinal velocity.

2. Longitudinal deceleration.

3. Steering wheel angle $\Rightarrow$ fixed control.

4. Steering wheel torque $\Rightarrow$ free control.

Measured parameters:

1. Vehicle response:

(a) lateral acceleration,

(b) yaw velocity,

(c) steering wheel angle $\Rightarrow$ free control,

(d) steering wheel torque $\Rightarrow$ fixed control.

2. Steering system:

(a) toe-steer angles, front axle,

(b) camber angles, front axle,

(c) steering wheel torque and angle,

(d) steering tie rod forces.

\subsection{Results}

\subsubsection{Standard front suspension lower wishbone rear bush stiffness, standard wheel offset}

In the standard configuration, the test car exhibited some steering drift to the left during braking as shown in Fig. 1; note that data-logging started at time zero, and the braking manoeuvre commenced at approximately $2 \mathrm{~s}$ into the logging time. The steering wheel angle measured under free control [13] also showed a negative steering wheel angle during braking. Under fixed control the yaw velocity initially increased and then decreased towards the end of the deceleration, but remained positive 


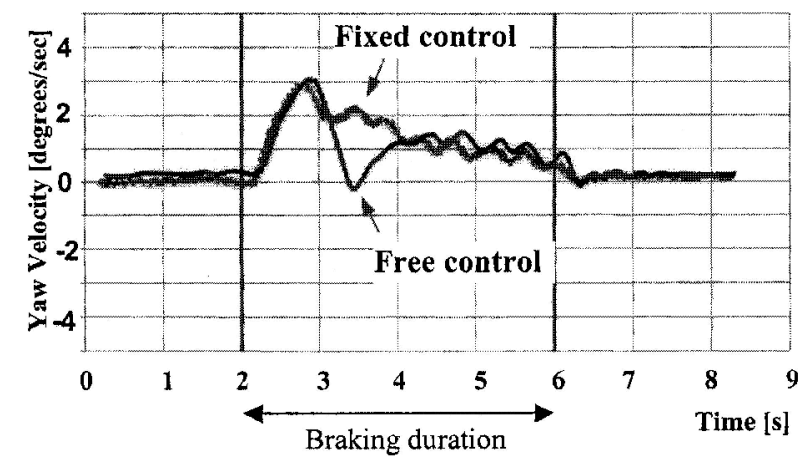

Fig. 1 Typical yaw velocity measurements, fixed and free control

throughout, indicating a continuous drift to the left. Under free control the yaw velocity characteristic also remained positive throughout, showing an initial increase, then a sharp decrease and then an increase before decreasing towards the end of the deceleration. Again this represented a drift to the left, but less continuous. The brake pressures were measured and found to be higher at the left front wheel than at the right front wheel, but, when the brake pipe connections were swapped from left to right, the steering drift to the left remained. This confirmed that the drift was not a result of side-to-side variation in brake actuation pressures.

Figure 2 shows the steering geometry of the test car, and Fig. 3 shows the measured steering tie rod forces during the test under fixed control, standard configur-

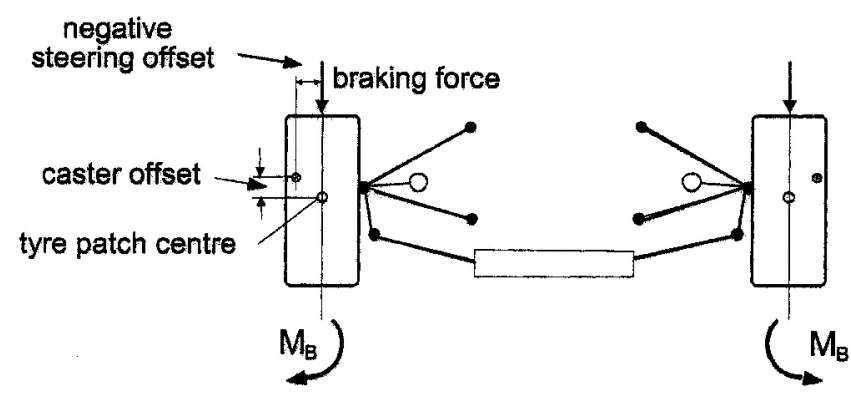

Fig. 2 Steering layout

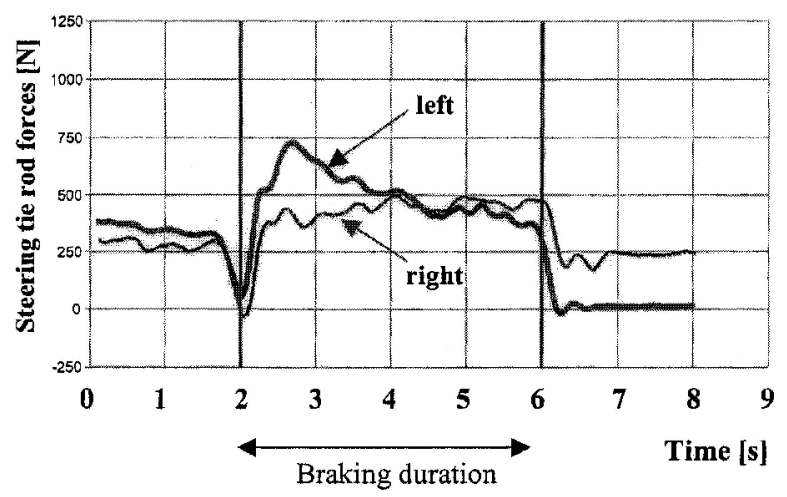

Fig. 3 Steering tie rod forces during the braking test, fixed control ation. Under deceleration the steering tie rod forces were in tension (positive), and, assuming no side-to-side brake force variation, the relative change in the left/right steering tie rod forces indicated that the steering offset varied during the braking test, although it remained negative.

The higher tension (positive) force in the left tie rod between the start and approximately $2 \mathrm{~s}$ into the braking under fixed control ( 2 and $4 \mathrm{~s}$ into the data-logging time shown in Fig. 3) indicated that the left wheel toe steer (inwards) exceeded the right wheel toe steer (inwards). This would appear to cause the vehicle to steer to the right during braking (assuming no other compliance steer influences and equal braking torque side to side), and not to the left as experienced by the driver and indicated in Fig. 1. The corresponding measured steering wheel torque under fixed control is shown in Fig. 4; a positive steering wheel torque over the same time period under fixed control indicates that a clockwise torque was required at the steering wheel, which again is consistent with steering drift during braking to the left.

Two seconds after applying the brakes, the force in the left tie rod decreased to less than that in the right tie rod, indicating toe steer to the left. The corresponding measured steering wheel torque then switched from negative to positive $2 \mathrm{~s}$ into the braking (Fig. 4), indicating that the drift commenced as drift to the right, but changed during the brake application to drift to the left. This was consistent with restraining the left toe steer and confirmed the relationship between tie rod force and toe steer angle.

When the vehicle was driven under free control, no significant difference between left and right tie rod forces was seen (Fig. 5). In this case, the vehicle would drift to the direction of the toe steer during braking, assuming that there were no other influences.

While investigating the standard configuration, the effect of front wheel orientation was also investigated more deeply. Any dynamic change in the caster angle is directly related to the longitudinal stiffness of any front suspension. The $x$ and $z$ axis deflections ( $x$ axis refers to the longitudinal direction and $z$ axis refers to the vertical direction) of the wheel centre-point were measured during braking, together with the $x$ deflection of the top of the suspension strut, relative to the zero position

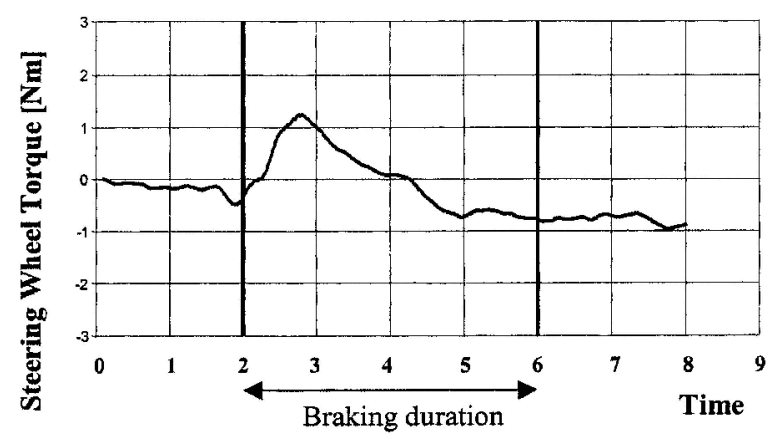

Fig. 4 Steering wheel torque, fixed control 


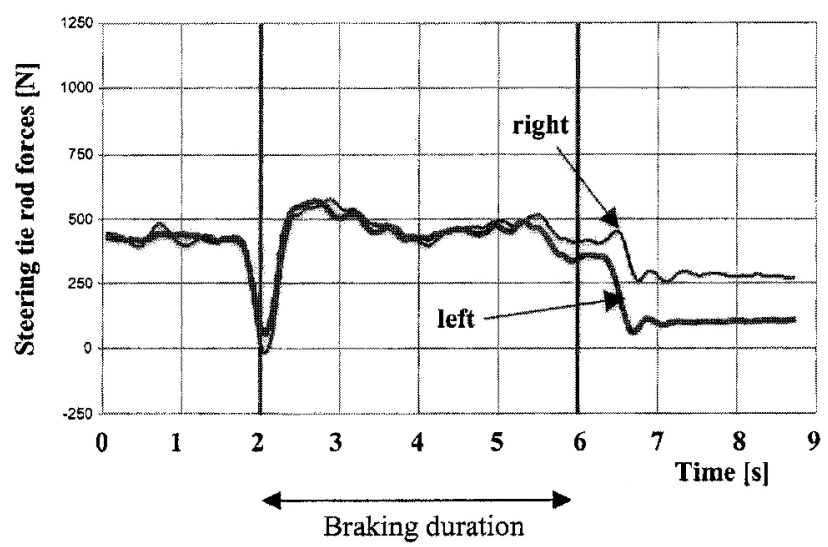

Fig. 5 Steering tie rod forces, free control

before the application of the brakes. Knowing this and the body pitch angle allowed the absolute caster to be calculated.

The dynamic change in the right wheel (rearward) longitudinal deflection was found to be initially larger, which would cause a drift to the right, as shown in Fig. 6. From these measurements the corresponding maximum caster angle changes were calculated, and are shown in Table 3.

Under dynamic braking, the right caster angle changed from +1.68 to $-0.8^{\circ}$, equivalent to a dynamic change in the caster offset from 9.38 to $-3.8 \mathrm{~mm}$. The left caster offset changed from +1.60 to $-0.45 \mathrm{~mm}$. A negative caster angle does not automatically lead to a change in steering direction, but a dynamic change from

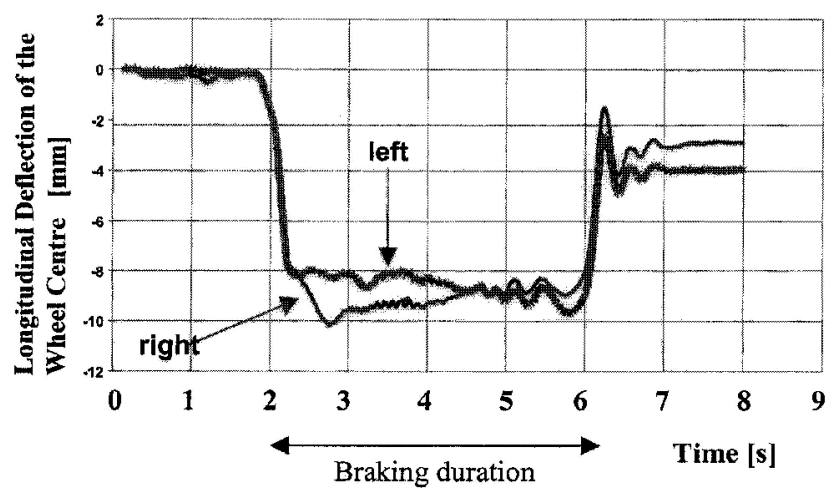

Fig. 6 Longitudinal deflection of the wheel centre-point positive to negative caster angle during braking will not improve vehicle stability.

\subsubsection{Standard front suspension lower wishbone rear bush stiffness, increased wheel offset}

The steering offset of the car was altered from -6.5 to $+1.5 \mathrm{~mm}$ by changing the wheel offset by fitting a spacer between both front wheels and the hubs, thereby changing the tyre contact patch (scrub radius) centre but not the kingpin geometry. Figure 7 shows the steering tie rod forces; during braking the tie rods were still in tension, though the magnitude of the tie rod forces was lower. The vehicle yaw velocity response was little changed from that shown in Fig. 1.

\subsubsection{Increased front suspension lower wishbone rear bush stiffness, standard wheel offset}

The compliance of the lower wishbone of the front suspension (both sides) was decreased by fitting a stiffer bush to the rear pivot. The steering tie rod forces and the toe-steer angles were measured during braking, and the results are shown in Fig. 8. The toe-steer angles with the original bushes and the stiffer bushes are compared in Figs 9 and 10. In this configuration, no steering drift during braking was generated that was discernible to the driver.

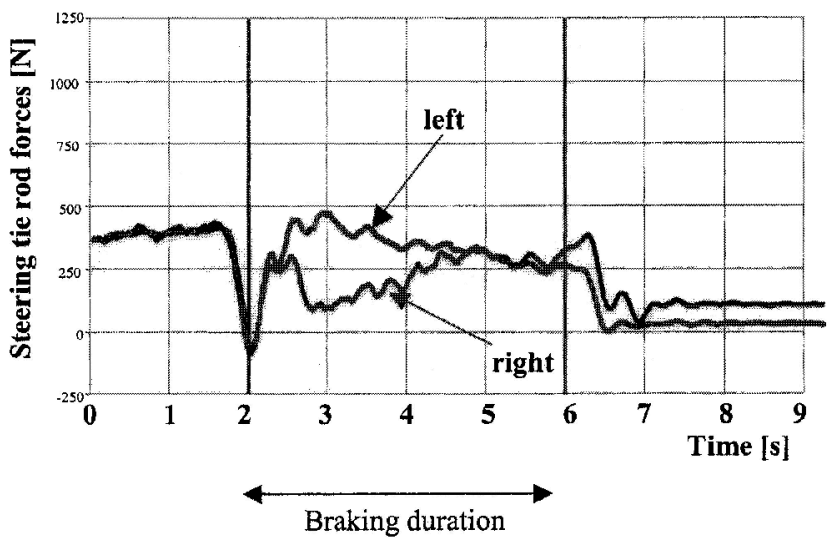

Fig. 7 Steering tie rod forces with additional spacers, fixed control

Table 3 Maximum values of the dynamic caster

\begin{tabular}{|c|c|c|c|c|c|}
\hline Definition & Nominal value & $\begin{array}{l}\text { Static } \\
\text { measured } \\
\text { value, } \\
\text { left track }\end{array}$ & $\begin{array}{l}\text { Static } \\
\text { measured } \\
\text { value, } \\
\text { right track }\end{array}$ & $\begin{array}{l}\text { Dynamic } \\
\text { measured } \\
\text { caster value, } \\
\text { left track }\end{array}$ & $\begin{array}{l}\text { Dynamic } \\
\text { measured } \\
\text { caster value, } \\
\text { right track }\end{array}$ \\
\hline Caster angle (deg) & 3.00 & 1.60 & 1.68 & -0.45 & -0.8 \\
\hline $\begin{array}{l}\text { Caster trail at wheel } \\
\text { centre }(\mathrm{mm})\end{array}$ & 0 & -2.96 & -1.48 & $\begin{array}{l}\text { Not } \\
\text { measurable }\end{array}$ & $\begin{array}{l}\text { Not } \\
\text { measurable }\end{array}$ \\
\hline Caster offset (mm) & 14.64 & 10.46 & 9.38 & -1.5 & -3.8 \\
\hline Scrub radius $(\mathrm{mm})$ & -6.05 & -6.695 & -6.55 & $\begin{array}{l}\text { Not } \\
\text { measurable }\end{array}$ & $\begin{array}{l}\text { Not } \\
\text { measurable }\end{array}$ \\
\hline
\end{tabular}




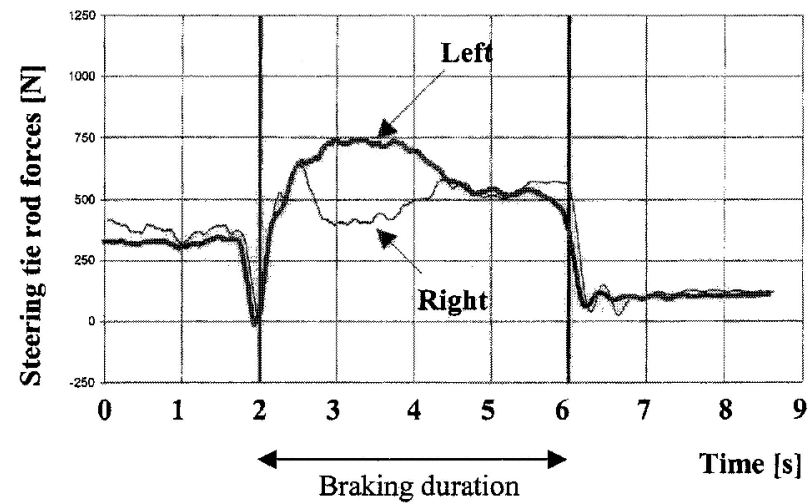

Fig. 8 Steering tie rod forces, with stiffer lower wishbone rear bushes, fixed control

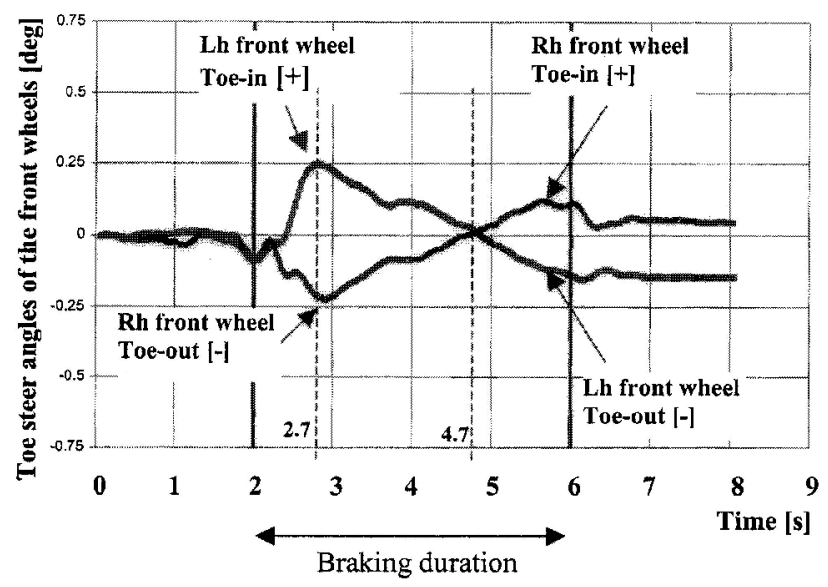

Fig. 9 Toe-steer angles, lower wishbone with standard rear bushes

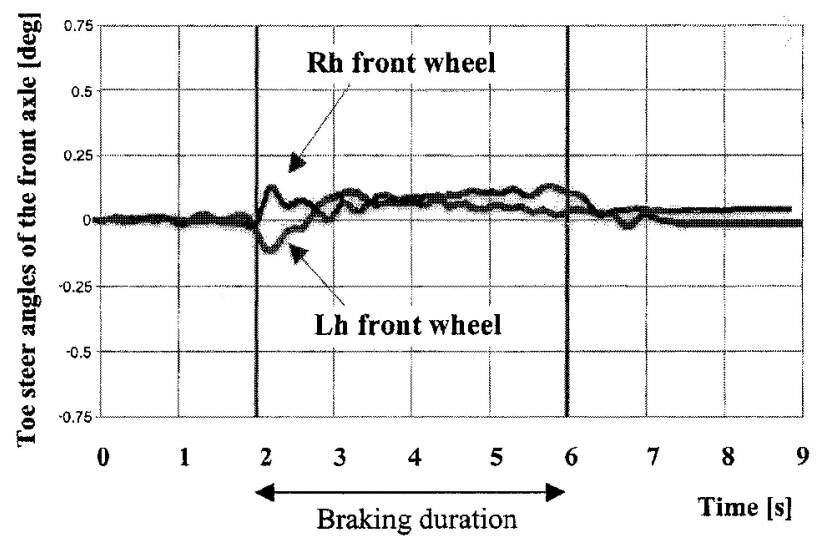

Fig. 10 Toe-steer angle, lower wishbone with stiffer rear bushes

\section{DISCUSSION OF RESULTS}

The parameter sensitivity studies showed that suspension compliance (as defined by the front suspension lower wishbone rear bush stiffness) and the steering offset (as defined by the wheel offset) were the two most significant parameters of the five investigated. These parameters were therefore considered for further investigation. A third factor, the fitment of a steering gear housing/engine subframe reinforced cover, was found to be significant but was not investigated.

The temperature of the tyres and brakes (cold or hot) was not found to be significant. This indicated that there were no side-to-side differences in braking torque generated by brakes in either the hot or the cold condition. The results clearly indicated that, for this particular design of suspension and steering geometry $(6 \mathrm{~mm}$ nominal negative offset), side-to-side variation in the braking forces at the front wheels was not a significant factor in the generation of steering drift during braking. This means that any attempt to enhance straight-line braking stability by close control of the frictional performance of the brakes would not, in this instance, be appropriate. Negative offset steering is therefore confirmed to have minimum sensitivity to side-to-side brake torque variation.

The suspension geometry toe-steer curve [defined as the way in which the toe-in setting of the front (steered) wheels changes as the suspension deflects in bounce or rebound] had no reproducible effect, which confirmed that the vertical deflection of the front suspension during braking did not affect steering drift. This was initially considered to be a possible important influence, because of the suspension movement of the steered wheels relative to the fixed steering rack.

Further investigation of the two most significant parameters found confirmed their importance in affecting steering drift during braking. What became very clear from the test data was firstly that changes in wheel position and orientation did occur during braking, and secondly that the magnitude of such changes varied during the braking manoeuvre. Thus, the drift experienced by the driver, and measured in terms of a number of parameters, was time-dependent, and appeared even to change from one direction to the other (right to left on the particular car tested).

The more detailed study of the front wheel geometry under braking loads enabled dynamic values of wheel orientation (caster) to be calculated and compared with the static measured and design values. Comparisons of caster angle showed that the measured value was below the design value (but still in specification), but under dynamic conditions it went very slightly negative. This will not directly affect steering drift during braking but is an indication of the magnitude of wheel deflection due to suspension compliance effects.

Changing the steering offset of the car by fitting a spacer between the front wheels and the hubs changed the tyre contact patch centre but not the kingpin geometry. However, this produced no change in the perceived drift of the car during braking. The spacer fitted changed the steering offset from negative to slightly positive, but this appeared to be insufficient to create any significant improvement. Concern would be raised if 
such a change were to be suggested as a route to improvement because of the stability associated with the negative offset design.

Addressing suspension compliance by inserting a stiffer bush in the rear pivot of the lower suspension arm minimized the deflection and controlled the wheel orientation better during braking, and reduced toe-steer effects to a negligible level. Not only did the deflection of this component relative to the subframe appear to generate large changes in suspension geometry, mainly in the side-to-side camber and steering offset, but the effect was also to change toe-steer angles during braking which actually reversed side to side during the braking manoeuvre. This result indicates that the major cause of steering drift during braking can therefore be concluded to be side-to-side dynamic variation in the deformation and deflection of suspension and steering components. Dynamic toe-steer changes are a direct result of such variation, and therefore minimizing differential deformation and deflection in the suspension geometry is very important.

\section{CONCLUSIONS}

The major cause of steering drift during braking is sideto-side dynamic variation in the deformation and deflection of suspension and steering components. The most effective means of controlling any tendency towards steering drift during braking is therefore to ensure, in the design of the steering and suspension system, that there is minimum side-to-side variation in suspension deflection and body deformation both statically and dynamically.

Steering drift during braking is primarily a toe-steer effect, where wheel movements in the longitudinal axis cause changes to steering geometry. It is the combination of wheel movements and associated toe steer on each side of the car that is important. Wheel orientation can also be affected, but, although steering offset is a significant parameter, it is not expected significantly to affect steering drift during braking unless there is a substantial change from negative to positive offset.

There are a number of parameters associated with tyre performance that could become significant if wheel orientation and steering geometry change sufficiently during braking. Although these have not been investigated here, study of the literature has confirmed their importance, and thus a need for further work. A further study of wheel movement and suspension deflection under forces that are representative of those generated during actual vehicle braking has therefore been recommended, and the results from such a study are presented in an associated publication. Such further experimental analysis will provide a significant database for the correlation of predictions made using computer simulation methods.
In this particular case, the lower wishbone rear bush was found to play a major role in controlling the wheel deflections, and, in terms of steering drift during braking, reducing the compliance by inserting a stiffer bush in the rear pivot of the wishbone offered a greater degree of robustness in the steering drift effects for this type of MacPherson strut suspension. Understanding the deflection characteristics of other types of suspension under braking offers a substantial challenge to the automotive design engineer.

\section{ACKNOWLEDGEMENTS}

This paper presents research carried out as part of an MPhil study with the University of Bradford, United Kingdom. The authors are grateful to all who contributed to the research, including staff in the Ford Motor Company, IKA (Aachen) and supplier companies. Thanks also go to the Directors of the Ford Motor Company for permission to publish this paper.

\section{REFERENCES}

1 Newcomb, T. P. and Spurr, R. T. A Technical History of the Motor Car, 1989 (IOP Publishing Limited).

2 Newcomb, T. P. and Spurr, R. T. Braking of Road Vehicles, 1967 (Chapman and Hall).

3 Chapman, B. J. and Hatch, D. Cast iron brake rotor metallurgy. IMechE, Braking of Road Vehicles Conference, 1976, paper C35/76.

4 Momoiyama, F. and Miyazaki, K. Compliance steer and road holding of rigid rear axle for enhancing the running straightness of large sized vehicles. SAE paper 933009, 1993.

5 Banholzer, D. Improving directional stability under braking. 5th International Technical Conference on Experimental Safety Vehicles, London, 4-7 June 1974, ESV-746076.

6 Yoshiroh, T., Keisuke, Y. and Masaru, K. The effects of the tyre camber angle on vehicle controllability and safety. SAE paper 860245, 1986.

7 Goddard, S. and Elwood, P. The impact of scrub radius on sport utility vehicle handling. SAE paper 982834, 1998.

8 Matyja, F. E. Tread design and belt angle effects on residual aligning torque. SAE paper 870423, 1987.

9 Pottinger, M. Tire/vehicle pull: an introduction emphasizing ply steer effects. Tire Sci. and Technol., July-September 1990, 18(3).

10 Pottinger, M. G. Ply steer in radial carcass tyres. SAE paper $760731,1976$.

11 Bastow, D. and Howard, G. P. Car Suspension and Handling, 1993 (SAE Pentech Press).

12 Grove, D. M. and Davis, T. P. Engineering Quality and Experimental Design, 1992 (Longman).

13 Klaps, J. Investigation of the effects of the longitudinal stiffness of the engine subframe and suspension system during straight-line braking in passenger cars. MPhil thesis, University of Bradford, United Kingdom, 1999. 